Abstract

\title{
1 Limited climate benefits of global recycling of pulp and paper
}

2 Stijn van Ewijk ${ }^{1,2,3}$, Julia A. Stegemann ${ }^{2}$ \& Paul Ekins ${ }^{3}$

$3 \quad{ }^{1}$ Center for Industrial Ecology, School of the Environment, Yale University, New Haven, CT, 06511,

4 USA

$5 \quad{ }^{2}$ Department of Civil, Environmental \& Geomatic Engineering, University College London, London,

6 WC1E 6BT, UK

$7 \quad{ }^{3}$ Institute for Sustainable Resources, University College London, London, WC1H ONN, UK

8 Corresponding author: Stijn van Ewijk (stijn.vanewijk@yale.edu)

\section{Abstract}

11 A circular economy is expected to achieve sustainability goals through efficient and circular use of materials. Waste recycling is an important part of a circular economy. However, for some materials the potential environmental benefits of recycling are unclear or contested. Here, we focus on the global paper life cycle, which generates $1.3 \%$ of global greenhouse gas emissions, and estimate the climate change mitigation potential of circularity. We model material use, energy use, and emissions up to 2050 for various levels of waste recycling and recovery. We show that emission pathways consistent with a 2-degree Celsius global warming target require strong reductions in the carbon intensity of electricity and heat generation. We also show that additional recycling yields small or negative climate change mitigation benefits when it requires high-carbon grid electricity and displaces virgin pulping that is powered by low-carbon pulping by-products. The results suggest that circular economy efforts should carefully consider the energy implications of recycling. 
Main

\section{Main}

Academic, industrial and government interest in a circular economy has rapidly increased over the past decade ${ }^{1}$. The idea of a circular economy responds to both environmental and economic challenges ${ }^{2,3}$ and has shaped recent policy efforts, most prominently in Europe and China ${ }^{4,5}$. Various initiatives, such as the non-profit Ellen MacArthur Foundation, have raised private sector interest in the circular economy ${ }^{6}$. Definitions and proposals for a circular economy typically advocate a range of approaches, including reduction, reuse, remanufacturing, and repair, but often emphasize recycling $2,7,8$.

There is concern over a lack of evidence regarding the technical feasibility and environmental benefits of circularity and, in particular, recycling ${ }^{9-11}$. Recycling of waste cannot create a perfect circle: growing demand for materials exceeds the waste available from past consumption, material is lost or degraded during processing, and the energy required for processing escalates with higher collection rates. Most importantly: an increase in circularity may require trade-offs such that a net reduction in environmental impacts cannot be guaranteed.

The emphasis on materials in the circular economy discourse is distinct from the climate change debate, which has tended to focus on energy use and electricity generation. The two are however inextricably linked: material production and consumption, including recycling, require significant amounts of energy. Recycling in the circular economy should thus be scrutinized regarding its energy requirements and greenhouse gas (GHG) emissions, with consideration of the implications for energy generation and supply.

Paper production is particularly relevant since global paper and paperboard use is likely to rise with increased demand for packaging, especially with current moves for substitution away from plastics. Paper is a renewable material and its production is uniquely powered by energy recovery from renewable pulping by-products. The impact of combined changes in material and energy use in the 
Results

global paper life cycle, including the recycling of wastepaper and the recovery of industrial waste flows, has not been explored.

Here, we analyse the climate change implications of greater material circularity in the global paper life cycle. We find that increased waste recovery does not significantly reduce GHG emissions because low-carbon chemical pulping, which is powered by burning its renewable by-product (black liquor), is displaced by recycled pulping, which tends to be powered by fossil fuels and grid electricity. Improvements in landfill practices yield greater emission reductions than waste recovery; by far the greatest reduction is achieved by switching to low-carbon energy sources.

In this article, we first present an estimate of GHG emissions from the global paper life cycle for 2012. We then show emissions up to 2050 based on a paper demand projection and trends for energy efficiency and carbon intensity. To describe the paper life cycle, we expanded material balances from the literature ${ }^{12,13}$ and modelled paper demand, energy use, and GHG emissions up to 2050 (see Methods). We estimated the impact of circularity by comparing a reference scenario with radical changes in material circularity, energy use, and landfill practices.

\section{Results}

Our results cover estimates for current GHG emissions from the global paper life cycle, projections of paper demand and life cycle GHG emissions up to 2050, and a comparison of the climate change mitigation potential of changes in material use, energy use, and landfill practices.

\section{Emissions from paper}

First, we estimated emissions from the global paper life cycle in 2012 (a process diagram is provided in Extended Data Figure 1). We calculated carbon emissions from fuel and electricity use for forestry and mining, pulping, papermaking, and printing, based on material balances ${ }^{13}$, energy flow data ${ }^{14}$, and process data ${ }^{15}$. We also calculated the net biogenic GHG emissions due to the landfilling of waste and storage of products. Forest carbon stocks were assumed to be stable and the combustion 
Results

of biofuels and waste was considered carbon neutral (see Methods). We calculated avoided emissions due to energy recovery from end-of-life discards and landfill gas, assuming the resulting electricity displaces electricity production from an average global fuel mix. We considered uncertainty in Specific Energy Consumption (SEC) values, Carbon Intensity $(\mathrm{Cl})$ values, and the parameters for the calculation of emissions from landfill.

Figure 1 shows GHG emissions (carbon dioxide $\left(\mathrm{CO}_{2}\right)$ and methane $\left(\mathrm{CH}_{4}\right)$ ) from the global paper life cycle in 2012. The total is dominated by bought fuels, bought electricity, and landfill gas. The major emission sinks are landfill and consumer stock. Recycling stock represents carbon that is kept instock because it is recycled into new products. The avoided emissions (not depicted in Figure 1) is 15 $\mathrm{Mt} \mathrm{CO}_{2} \mathrm{e}$ for energy recovery of end-of-life discards and coincidently, also $15 \mathrm{Mt} \mathrm{CO}_{2} \mathrm{e}$ for energy recovery from landfill gas. A comparison with global studies ${ }^{16-19}$ (see Supplementary Table 1) shows that our estimates fall in between previous estimates for the six emission categories, except for the estimate of consumer stock, which was calculated in only one previous study ${ }^{18}$, based on an exceptionally low rate of Net addition to Stock (NaS) of approximately $3 \%$ as compared to $9 \%$ in the present study.

The uncertainty for the estimate for landfill gas (the error bar in Figure 1) is large because the calculation depends on a range of parameters for which precise global estimates are not available.

The uncertainty is skewed towards higher estimates since the calculation involves the multiplication of many parameters with symmetrical uncertainty ranges. The level of uncertainty could be reduced through better data collection on methane generation and capture from landfills. The uncertainty in the emissions from bought fuels and electricity use can be improved through more comprehensive reporting of energy flows associated with Combined Heat and Power (CHP) (See Supplementary Note 1).

The results represent global average paper production based on the global average $\mathrm{Cl}$ for grid electricity. In practice, the $\mathrm{Cl}$ of grid electricity varies by country and a single paper mill may have a 
Results

green electricity contract. However, the purpose of our analysis is to assess the impact of paper recycling and recovery for the global economy; evidently, not all industries can be immediately supplied with low-carbon electricity. In the absence of a well-functioning green electricity market, every unit of demand for electricity drives supply from a mix of low- and high-carbon electricity sources. For these reasons, we used the average global $\mathrm{Cl}$ of electricity in our analysis.

GHG emissions of the paper life cycle are relatively low due to intensive use of biomass (derived from the paper production process) for energy, assuming sustainable yield and constant forest carbon stocks (see Methods). The industry uses black liquor, the biogenic by-product from wood pulping, to generate electricity and heat. In our analysis, black liquor is categorized as mill waste and not as fuel (See Methods). The bought fuels include coal (95 kg CO2/GJ), peat (106 kg CO $2 / G J)$, natural gas ( $\left.56 \mathrm{~kg} \mathrm{CO}_{2} / \mathrm{GJ}\right)$, and biomass (carbon neutral); the average $\mathrm{Cl}$ of bought fuels is about a third lower than that of coal. The $\mathrm{Cl}$ of the various energy inputs has a great impact on the overall emissions: for pulping, papermaking, and printing, bought fuels supply 2.5 times more energy than bought electricity; however, GHG emissions of electricity are higher because the $\mathrm{Cl}$ of bought electricity is 3.9 times higher.

\section{Projected emissions}

Second, we estimated future paper demand and the associated emissions. The estimate of future demand considered the relationship between material use and income, economic forecasts ${ }^{20}$, saturation of material demand in rich countries, and substitution of paper products with alternatives (mainly through digitization). We projected per capita demand of five paper grades in OECD and non-OECD countries and combined these projections with population forecasts ${ }^{21}$ to calculate total demand. We present low, middle, and high estimates for per capita consumption and the population projections (see Methods).

Figure 2 shows the projections of per capita demand per paper grade (panel a to e) and the resulting total global paper demand projection (panel f). Global demand features strong growth, mainly 
Results

because of the high growth in per capita paper and board packaging demand - the largest paper grade by volume - in non-OECD countries, and the simultaneous large increase in population in the same geography. The most recent figures for global paper consumption fall behind our projection ${ }^{22}$ but the recent trend to phase out plastics may reinforce paper demand ${ }^{23}$. Our middle projection for demand in 2050 ( $878 \mathrm{Mt}$ ) falls in between previous projections, which ranged from 611 to around 960 Mt in 2050 (Supplementary Table 2).

Future energy use and emissions were calculated based on demand growth and expected technological change, which were captured as three levels of change - standard, ambitious, and radical - for each of the three aspects of the life cycle: material flows (efficiency and circularity), energy use (efficiency and carbon intensity), and landfill practices (landfill design and operation). The three levels of change and the three aspects of the life cycle together yield $3^{3}=27$ scenarios (Supplementary Table 3). The main scenarios combine consistent levels of change for all three aspects: Reference (REF) features standard change, Middle (MID) features ambitious change, and Maximum (MAX) features radical change for material use, energy use, and landfill practices.

The three levels of change were defined as follows. First, standard change represents a continuation of current trends, whether for recycling and recovery, energy efficiency, or carbon intensity. Standard change assumes no change in policy beyond what has been observed in the past. Second, ambitious change sits halfway in between standard and radical change, approximately representing half the effort that would be required to achieve radical change. The ambitious effort is, in effect, defined by the standard and radical efforts. Third, radical change goes up to practical limits: for material use, recycling is limited only by additions to stock and processing losses; for energy use, the carbon intensity is reduced to near-zero; for landfill practices, best available technology is adopted globally.

Figure 3 shows material flows in the global paper life cycle and illustrates the difference between material use in 2012 (panel a) and, after radical change, in 2050 (panel b). The two diagrams are 
Results

normalized to 100 units of paper production to allow direct comparison. Our model is based on more detailed material flows, which are listed in Supplementary Table 4. Figure 3 reflects the most important features of radical change in material use. Per unit of production, recycling is almost doubled, virgin fibre inputs are almost halved, and all waste that cannot be recycled into new paper is used in other energy or material recovery. The amount of mill production waste available for energy recovery is lower in 2050 than in 2012 because of a decrease in chemical pulping and generation of black liquor.

We compare our emission projections against a GHG emission target for 2050, based on the global climate change mitigation pathways for a $44-68 \%$ chance of limiting average global warming to 2 degrees Celsius ${ }^{24}$. Our target setting approach assumes proportional emission reduction responsibilities: each sector, system, or life cycle must achieve the same relative reduction as required globally. The paper life cycle was responsible for $1.3 \%$ of global GHG emissions in 2012 and, under our proportional target setting approach, is allowed an equal fraction of global GHG emissions in 2050. We express the target as a range based on the variations in required reductions in different climate change scenarios. The target calculation is detailed in Supplementary Table 5.

Figure 4 shows the emission estimates for the three scenarios and the 2050 carbon emission target range consistent with a limit of 2 degrees Celsius average global warming. In the REF scenario, net emissions grow slightly from $721 \mathrm{Mt} \mathrm{CO2e} \mathrm{in} 2012$ to 736 Mt CO2e in 2050. In the MID scenario, GHG emissions are much lower and fall within the target range. The net emissions of the MAX scenario fall well below the target range and just below zero, which suggests that paper production and consumption can potentially serve as a carbon sequestration strategy. The MID and MAX scenarios meet the target but feature annual decarbonisation rates of respectively $2.5 \%$ and $6.0 \%$ for both bought fuels and grid electricity, which imply profound changes in both the paper and electricity sector. 
Results

We assessed the robustness of our results by running the main scenarios for variations in paper demand, and fuel and electricity use (see Methods). An overview of the results is provided in Supplementary Table 6. We find that the REF scenario never meets the target. For the MID scenario, emissions fall within or below the target range in most cases, but not for a combination of high paper demand and an increased reliance on grid electricity instead of on-site electricity generation from fuels. The emissions in the MAX scenario always fall below the target range, generating 284$422 \mathrm{Mt} \mathrm{CO}{ }_{2} \mathrm{e}$ less than allowed. In summary, the REF scenario is insufficient, and the MAX scenario is sufficient for the global paper life cycle to achieve reductions consistent with 2 degrees global warming.

\section{The impact of circularity}

The three main scenarios describe simultaneous and consistent changes in material flows, energy use, and landfill practices. To reveal the impact of greater recycling and recovery, we compared all combinations of standard and radical change in material use, landfill practices, and energy use, as shown in Figure 5 (scenarios a to $\mathrm{h}$ include main scenarios REF and MAX). First, a comparison between scenarios with standard (scenarios a-d) and radical (scenarios e-h) change in material use reveals that maximum recycling and recovery yields higher GHG emissions, all else being equal. This challenges the notion that recycling benefits the climate. Further comparison of the scenarios reveals that radical change in energy use consistently yields very large reductions in emissions, and radical change in landfill practices yields much smaller but still significant reductions.

Why does greater recycling and recovery increase emissions? Figure 6 shows a comparison of emissions in 2050 between the REF-scenario (standard change for all aspects) and the scenario featuring radical material use (but standard change in energy use and landfill practices). Radical change in material use leads to significant reductions for recycling stock, fuels, and landfill gas, but also to higher emissions from electricity and landfill stock. The increase in electricity use is the consequence of the lower availability of black liquor - the by-product of virgin pulping - for the 
Results

194

195

196

197

generation of electricity and heat and causes an additional $105 \mathrm{Mt}$ of $\mathrm{CO}_{2} \mathrm{e}$. The reduction in landfill stock occurs because recycling instantly limits the sink function of the landfill but only limits the source function of the landfill (methane generation) with a considerable time delay.

The impact of greater recycling on GHG emissions is dependent on how the paper sector responds to a decrease in electricity and heat from black liquor recovery. We modelled three energy supply responses: 1) an increase in the fraction of bought fuels proportional with a decrease in black liquor, maintaining the level of on-site generation of power and heat, and requiring increased use of CHP at recycling mills, 2) a constant fraction of bought fuels, with the decline in on-site power generation compensated for with an increase in the fraction of bought electricity, 3) a decline in the fraction of bought fuels proportional with the decline in black liquor, with the decline in on-site power generation compensated for with bought electricity (see Extended Data Figure 2). For all three options, the emission reduction potential of greater recycling is small or negative: under radical material use, the first option leads to $5 \%$ lower emissions than REF, the second option to $10 \%$ higher emissions (the default in our model, displayed in Figure 6), and the third option to $19 \%$ higher emissions.

Emissions that are avoided because of electricity exported from the paper system, which displaces average global electricity, were not aggregated with other emissions because they should be considered in relation to the GHG target for the electricity sector. Under the REF scenario, avoided emissions equate to $4 \%$ to $8 \%$ of the net paper life cycle emissions, depending on the year. Under radical material use, avoided emissions hardly matter, because increased recycling leads to a decrease in energy recovery from both end-of-life discards and landfill; a more circular life cycle leads to less avoided emissions in the electricity sector. Besides, the amount of avoided emissions in 2050 is relatively low due to the projected decline in the carbon intensity of grid electricity (see Methods). 
Discussion

\section{Discussion}

220 We compared our results with previous estimates in the literature. A simple eight-parameter model

221 of the global paper life cycle by Allwood et al. ${ }^{17}$, when reproduced and parametrized with a higher

222 recycling rate, reveals a similar increase in emissions through recycling, though it is not discussed by

223 the authors. However, Life Cycle Assessment (LCA) studies tend to present recycling more favourably

224 than in our analysis, for various reasons. First, LCA studies tend to assume that greater recycling increases forest carbon stock or displaces fossil fuels when the wood is not used for pulp but for energy. At the global scale, such an assumption cannot be validated, because of the uncertainty in current forest carbon stocks, the major role of forest management, and the complex drivers of deforestation (see Methods).

Because of forestry-related assumptions, LCA studies commonly present negative emission intensities for recycling ${ }^{25,26}$. The EPA Waste Reduction Model (WARM) ${ }^{26}$ presents life cycle GHG emissions for virgin production of $0.8-2.4 \mathrm{tCO} 2_{\mathrm{e}} / \mathrm{t}$ paper, with an increase in recycling leading to gains of -3.3 to $-2.4 \mathrm{tCO} 2_{\mathrm{e}} / \mathrm{t}$ paper, driven largely by forest carbon gains of -2.8 to $-1.8 \mathrm{tCO} 2 \mathrm{e} / \mathrm{t}$ paper. For the aggregate paper system, a study for Denmark ${ }^{27}$ finds that 'increased recycling', with the collection rate going from $51 \%$ to $72 \%$, reduces global warming potential by $10 \%$, assuming wood is diverted to energy use and displaces fossil fuels. Our scenario for ambitious scenario material use features a similar increase in the collection rate (from $49 \%$ to $75 \%$ ), but an increase in emissions of approximately $5 \%$.

A second difference between our analysis and typical LCA studies is that we use a temporally specified carbon target. In LCA studies, future emissions from consumption in the reference year are treated the same, regardless of when they will occur, but we calculated emissions from the total system that happen as a result of all consumption up to 2050 , including delayed landfill gas emissions. In LCA, increased recycling yields immediate benefits due to reduced landfill gas emissions, but in our study, this benefit occurs with a delay and partly after the target year 2050. In 
Discussion

our analysis, the reduction in landfill gas plays a limited role in meeting the emission target, which is not favourable to our evaluation of recycling.

We estimated the impact of the temporal boundaries of our study by running the model again under the assumption of immediate release of landfill gas (as in most LCAs), by allocating landfill gas emissions up to 2100 to the year of waste disposal to landfill. This approach leads to estimates of net emissions that make recycling appear slightly more beneficial: radical material use yields a $3 \%$ reduction in net emissions, compared to a $10 \%$ increase in emissions previously (see Figure 6). However, this shows that irrespective of temporal assumptions, the reduction in emissions is very small and nowhere near the emission reduction required to meet the carbon targets for 2050. An overview of the comparison is provided in Supplementary Table 7.

Our analysis reveals important knowledge gaps, including the understanding of the forest carbon balance, the drivers of deforestation, and the accuracy of data for methane generation and capture from landfills. Such data may be more readily available at the national or local level and our global analysis is not always representative of the national and local possibilities: increased circularity of the pulp and paper industry, including through greater recycling, can bring benefits in many cases, not least for climate change and forest conservation. The extent of such benefits greatly depends on (local) forest management, the fuel mix for the onsite generation of electricity and heat, and the carbon intensity of the relevant electricity supply.

Our results illustrate that greater circularity through increased recycling and recovery is not a straightforward recipe for global GHG reductions. In our analysis, landfill practices mattered more, and energy use mattered most. The dominant role of energy use as a driver of GHG emissions makes decarbonising the energy supply an imperative for emission reductions. In theory, global paper production could be exclusively powered by onsite electricity generation from renewables; in practice, there are major barriers to achieving this, not least competing demand from other sectors for renewable energy sources, primarily biomass. Most importantly, whether for the grid or onsite 
Methods

electricity generation, decarbonisation of energy supply is essential to meet climate change targets circular use of materials cannot remove this requirement.

Our results suggest that the impact of greater circularity needs to be assessed for materials and products individually. For industries that do not rely on renewable energy for virgin production, recycling may yield greater benefits. For industries with non-energy GHG emissions, such as the cement sector, which generates carbon emissions from calcination of limestone, the climate change mitigation challenge is altogether different. To achieve the internationally agreed GHG emission reductions, circular economy efforts should consider the best impact reduction strategies for materials and products individually. Promising strategies besides recycling and recovery of waste include decarbonisation of the energy supply, changing process technologies and feedstocks, and shifting demand away from the most impactful materials.

\section{Methods}

The methods section covers the estimation of energy use and GHG emissions in the base year, the paper demand projection, and the GHG emissions projection.

\section{Energy and emissions}

Energy use and GHG emissions were calculated for extraction, pulping, making, printing, use, and end-of-life discards of paper. The emissions sinks and sources include: bought fuels to generate electricity and heat for paper mill operations; bought electricity to power pulping, papermaking, and printing; biogenic carbon stocks and flows from forestry, in-use products, recycling, and landfill; avoided emissions through energy recovery of consumer waste and landfill gas. Avoided emissions, due to displacement of electricity production from an average global fuel mix, were not aggregated with other emissions to avoid inconsistencies with the GHG target, which is for the paper life cycle only and not for the electricity sector in which the displacement takes place. 
Methods

Forest carbon stocks were assumed stable and the outputs from energy recovery of biogenic waste and biomass carbon neutral. We did not include an estimate of the carbon impact of forestry for paper production because we found that 1) estimates for global carbon sinks and sources are highly uncertain and in contradiction ${ }^{28-30}, 2$ ) forest type and forest management have a major impact on carbon stocks but cannot be directly related to timber extraction for paper, and 3) commercial logging is only one of many drivers of deforestation, which complicates allocation of deforestation impacts to the paper industry ${ }^{31,32}$. A previous study on the paper life cycle in the United States presents a zero estimate for forestry impacts ${ }^{33}$ and a global study confirms it is 'not possible to develop a global estimate' of paper sector impacts on global forestry ${ }^{18}$.

Only $\mathrm{CO}_{2}$ and $\mathrm{CH}_{4}$ were included in the analysis since other GHGs make a very small contribution to emissions in the global paper life cycle. Emissions from transport are excluded since the literature suggests these are not significant compared to total life cycle emissions ${ }^{26,34,35}$, and insofar they occur, they should not be expected to differ significantly between the scenarios for material use, energy use, and landfill practices ${ }^{26}$. Indirect emissions associated with the production of fuels, materials, equipment, factories, and infrastructure are not included because the amount is expected to be small relative to the energy-intensive pulp and paper processing.

For extraction activities, the estimate of energy use is based on virgin fibre quantities and SEC values from the literature ${ }^{36}$. For pulp, paper, and print, the electricity and heat demand is calculated bottom-up by multiplying material flows with SEC values ${ }^{37,38}$, as well as top-down based on reported sectoral energy consumption data ${ }^{14}$. The two estimates are compared to refine the SEC values and recalculate the energy consumption for each process. The $\mathrm{Cl}$ of fuels is based on IPCC factors ${ }^{39}$ and the $\mathrm{Cl}$ of bought electricity is calculated from global electricity production ${ }^{40}$ and electricity sector emissions ${ }^{41}$.

The energy supply for the pulp, paper, and print sector covers on-site power and heat generation from fuels and mill waste, as well as electricity purchases. We identified three main categories of 
Methods

energy inputs. First, bought fuels such as coal and gas are obtained externally. They include waste from other sectors but not from the paper life cycle. Second, mill waste covers industrial waste from the paper life cycle that is converted into electricity and heat. It includes black liquor, recycling sludge, and sludge and rejects. Lastly, bought electricity refers to electricity from the grid and excludes electricity that is generated on-site by paper mills.

We calculated biogenic carbon flows from landfill based on IPCC methodology ${ }^{42}$. Equation 1 estimates $\mathrm{CH}_{4}$ emissions in year $t$ due to landfilling of waste $W_{x}$ in year $x$, depending on the half-life factor (k), the methane correction factor (MCF), degradable organic carbon content (DOC), the fraction of DOC dissimilated (DOCf), the fraction of $\mathrm{CH}_{4}$ in the gas (F), the methane capture rate (R) and the methane oxidation rate (OX). The mass ratio of methane over carbon is $16 / 12$. To arrive at the total $\mathrm{CH}_{4}$ emissions in year $t$, the values for landfill emissions for the year $t$ from each landfill deposit in year $x$ are summed. Aerobic decomposition of paper and the combustion of landfill gas was considered carbon neutral and the carbon that is stored indefinitely in landfills is accounted for as a negative emission.

\section{Equation 1.}

$$
S(t, x)=\left(\left(\left(1-e^{-k}\right) * W_{x} * M C F * D O C * D O C f * F * \frac{16}{12} * e^{-k(t-x)}\right)(1-R)\right) *(1-O X)
$$

Biogenic carbon stocks due to long-term use of paper products, product storage in landfills, and repeated use of fibres (recycling) were calculated based on product carbon content. The net addition to carbon stock due to repeated use of fibres was calculated by subtracting the carbon content of recycling volumes in the previous year from volumes in the current year. In other words, if recycling increased from $200 \mathrm{Mt}$ to $205 \mathrm{Mt}$, this was accounted for as an increase of in-use stock of paper by 5 $\mathrm{Mt}$, and an associated increase of in-stock carbon. Energy recovery from end-of-life discards and landfill gas can displace the use of fossil fuels and avoid emissions; the avoided emissions were calculated by multiplying the energy outputs from energy recovery with the $\mathrm{Cl}$ of global electricity. 
Methods

341 We considered parametric uncertainty for all emission categories shown in Figure 1. The SEC values were assumed to have an uncertainty of $\pm 10 \%$ based on a similar variation between datasets ${ }^{43}$. For the $\mathrm{Cl}$ values, based on the same source, an uncertainty of $\pm 5 \%$ was assumed for fuels for extraction activities. For the $\mathrm{Cl}$ of all other fuels, the uncertainty was assumed $\pm 20 \%$, to account for the estimations that were necessary to address energy data gaps (see Supplementary Note 2). Finally, for biogenic carbon, ranges were defined for all parameters. For carbon storage due to recycling, no uncertainty ranges were considered, because the estimates are very small. Detailed calculations and parameter values for energy and emissions are included in Supplementary Note 1. A summary of all model parameters is provided in Supplementary Tables 8-10.

\section{Demand projection}

351 The paper demand projection was based on historical consumption trends, saturation and substitution effects, and population and income projections. For five paper grades and two country groups (OECD and non-OECD), we analysed whether consumption grows proportionally with Gross Domestic Product (GDP) from 1996 to 2007 (until the financial crisis) and assessed whether deviations are the result of saturation or substitution. We then established, on a per-capita basis, the likely consumption levels for those paper grades and country groups that do not grow proportionally with income. The paper demand in between the base-year and 2050 was interpolated using exponential growth curves. Population and economic growth projections were taken from the $\mathrm{UN}^{21}$ and the OECD ${ }^{20}$. We used uncertainty ranges of $\pm 20 \%$ for per capita consumption for grades whose demand does not grow proportionally with income. We also used the uncertainty ranges provided by the population and economic growth estimates. The resulting projections were shown in Figure 2. Detailed calculations and parameters values are provided in Supplementary Note 1. 
Methods

\section{Emissions projection}

365

366

The modelling scenarios are constructed based on parameter sets for material use, energy use, and landfill practices. For each set, the parameters can be at a level consistent with standard, ambitious, and radical change. The full set of scenarios is summarized in Supplementary Table 3 . There are $3^{3}=$ 27 scenarios in total but only the three main scenarios share the same levels for each parameter set. For example, for MAX, the parameters for material use, energy use, and landfill practices are all at the radical change level. The following section describes the three individual parameter sets; when figures are provided for the years 2012 and 2050, the values for intermediate years are based on linear interpolation, unless stated otherwise. A summary of all model parameters is provided in Supplementary Tables 8-10.

The parameters for material use are based on a description of 2012 materials flows ${ }^{13}$ and a scenario with maximum recovery and recycling of all waste flows ${ }^{12}$. The parameters for standard and ambitious change were set by equally partitioning the gap between current and best possible performance. Standard and ambitious change close respectively one third and two-thirds of the gap between recycling or recovery performance in $2012\left(R_{2012}\right)$ and the maximum recycling or recovery potential (RP) in 2050. Equation 2 and Equation 3 describe the calculations for the recovery potential $\mathrm{R}$ of waste flow $\mathrm{i}$ for the use of waste under standard and ambitious change in material use.

\section{Equation 2.}

$$
R_{\text {Standard }, i}=R_{2012, i}+\frac{1}{3} *\left(R P_{i}-R_{2012, i}\right)
$$

\section{Equation 3.}
The parameterization is derived from the performance gap between high-income and low-income countries, and the maximum technical performance. Standard change implies global performance 
Methods

will be raised to the levels currently achieved in high-income countries. For example, the global recycling rate is raised to $68 \%$ in 2050 , which is about the average performance across OECD countries in 2012. Ambitious and radical change go beyond the performance currently observed across the developed world, with radical change implying that the best performance observed in the base year, for particular cases or countries, is achieved globally.

The parameter settings for energy use are based on experience curves and exponential decarbonisation rates. The experience curves capture the improvements in energy efficiency as a function of cumulative production. Experience curves are widely used to assess cost reductions for energy technologies ${ }^{44-47}$ but also for energy efficiency trends in industrial sectors ${ }^{48,49}$. Equation 4 and Equation 5 describe industrial experience curves for final energy (electricity and heat) in the pulp, paper, and print sector, based on the SEC in year $t\left(\mathrm{SEC}_{\mathrm{t}}\right)$, Cumulative Production in year $\mathrm{t}\left(\mathrm{CP}_{\mathrm{t}}\right)$, and experience index (b) ${ }^{48,49}$. The Learning Rate (LR) indicates the relative reduction per doubling of cumulative production.

\section{Equation 4.}

\section{Equation 5.}

$$
S E C_{t}=S E C_{0} * C P_{t}^{b}
$$

The historical comparison requires constructing a complete energy balance for an earlier year, which we chose to be 1971 , the earliest year for the IEA energy data ${ }^{14}$. We used the same methods and data sources as for the energy balance in the base year. To account for pre-1971 paper consumption, we assumed a linear increase in consumption from 0 in 1900 to the earliest reported value in 1961. Comparison of the balances reveals that cumulative production has grown more the four-fold from 1971 to 2012, whilst the SEC for final energy consumption was reduced by $14 \%$. The resulting learning rate is $6.8 \%$, i.e. with every doubling of production, the SEC decreases with $6.8 \%$. 
Methods

411

412

413

414

415

416

417

418

419

420

421

422

423

424

425

426

427

428

429

430

431

432

433

434

435

This learning rate was applied to model standard change, whilst ambitious and radical change feature learning rates of $10.2 \%$ and $13.5 \%$ respectively (the latter being a doubling of the standard learning rate).

Not only energy efficiency is expected to improve in the future: the carbon intensity of energy supply is also likely to change. For both fuels and electricity, the decarbonization rates were assumed to be $1.0 \%$ annually and $32 \%$ by 2050 (standard change), $2.5 \%$ annually and $62 \%$ by 2050 (ambitious change), and $6.0 \%$ annually $90 \%$ by 2050 (radical change). The standard rate is generalised from the historical development of the carbon intensity of bought fuels in the paper industry and the global electricity mix in the years 2002-2012 (Extended Data Figure 3). The rate for radical change was picked to be approximately consistent with climate targets; the rate for ambitious change is in between standard and radical.

Landfill practices are expected to improve in the future; we modelled this by changing the Methane Correction Factor (MCF), which captures the difference between dumps and engineered landfills, and the methane recovery rate $(R)$, which describes the fraction of landfill gas that is captured and recovered. The shift towards deep managed landfill is captured by increases in the MCF from 0.7 in 2012 to 0.8 (standard), 0.9 (ambitious), and 1.0 (radical) in 2050. The fraction of landfill gas that is captured was set to rise from a quarter in 2012 to 0.5 (standard), 0.75 (ambitious), and 0.8 (radical) in 2050. These fractions are based on the average performance of basic landfills (ambitious change) and engineered landfills (radical change) ${ }^{50}$.

The uncertainty in the projections of future emissions is captured in various ways. First, the comparison between the scenarios provides an indication of possible outcomes and, therefore, of the uncertainty range. Second, for each scenario, uncertainty is captured by the range for the paper demand projection. Third, three options for fuel use scenarios are considered (see Supplementary Figure 3). Fourth, the carbon target is defined as a range, based on the various emission pathways collated by the IPCC ${ }^{51}$, which captures the considerable uncertainty associated with climate change 
Methods The authors declare no competing interests. of the analysis. the grid cannot provide).

\section{Data availability} corresponding author on reasonable request.

\section{Author contributions}

\section{Competing interests}

modelling. Supplementary Table 6 summarizes how the sources of uncertainty affect the outcomes

Under exceptional circumstances, the options for fuel use developments lead to counterintuitive results: option 3 leads to a higher fraction of bought fuels than option 1 when the fraction of mill waste in total energy supply increases. This occurs when energy efficiency improvements outpace increases in recycling. There is also the possibility of heat demand exceeding supply due to a combined shift in energy provision and process requirements, which occurs when radical change in material use coincide with fuel use option 3 . The model contains a provision that keeps the supply of bought fuels at the minimum that is required to meet the demand for heat (which electricity from

The datasets generated during and/or analysed during the current study are available from the

S.V.E. designed the model, analysed the results, and drafted the manuscript; J.S. and P.E. contributed to the model design and analysis and revised the manuscript. 
Methods

Figure 1. GHG missions from the global paper life cycle in 2012.

The error bars show the parametric uncertainty in the estimate for fuels $(-82 /+98)$, electricity $(-$ $22 /+23)$, consumer stock $(-5 /+5)$, landfill stock $(-6 /+11)$, and landfill gas $(-117 /+191)$.

Figure 2. Projections of per capita global paper demand.

Panels a-e show demand by grade and income group. Panel $\mathbf{f}$ shows total global paper demand. The dashed lines in all panels are for low and high estimates.

Figure 3. Current and circular use of materials.

Panel a shows material flows in 2012; panel b shows material flows in 2050 after radical change in material use. The flows in both panels are normalized to 100 units of production.

Figure 4. Emissions in 2012 and in 2050 for three main scenarios.

The net emissions are indicated on top of the bars. The target range is for annual emissions from the global paper life cycle in 2050 consistent with a 2-degree Celsius global warming target.

Figure 5. The drivers of paper life cycle emissions.

Comparison of GHG emissions in 2050 for eight scenarios that feature all combinations of standard and radical change in material use, energy use, and landfill practices.

Figure 6. Breakdown of emission savings due to circularity.

Comparison of net emissions in 2050 in the REF scenario with the scenario featuring radical change in material use, and standard change in energy use and landfill practices. 
Methods

\section{Extended data figure legends}

Extended Data Figure 1. Paper life cycle system.

Incineration refers to Municipal Solid Waste (MSW) incineration with or without energy recovery.

Other recovery refers to material recovery except paper recycling.

Extended Data Figure 2. Options for meeting energy demand.

An increase in recycled pulping leads to a decline in virgin pulping and lower availability of virgin pulping mill waste for energy generation. In response, various fractions of demand can be met with bought electricity or bought fuels.

Extended Data Figure 3. Projection for the carbon intensity of electricity and fuels.

The scenarios correspond to annual reductions of the carbon intensity of bought electricity and bought fuels by $1.0 \%$ (standard), $2.5 \%$ (ambitious), and $6.0 \%$ (radical). 


\section{References}

1. Geissdoerfer, M., Savaget, P., Bocken, N. M. P. \& Hultink, E. J. The Circular Economy - A new sustainability paradigm? J. Clean. Prod. 143, 757-768 (2017).

2. Kirchherr, J., Reike, D. \& Hekkert, M. Conceptualizing the circular economy: An analysis of 114 definitions. Resour. Conserv. Recycl. 127, 221-232 (2017).

3. Van Ewijk, S. Resource efficiency and the circular economy Concepts, economic benefits, barriers, and policies. (2018).

4. McDowall, W. et al. Circular Economy Policies in China and Europe. J. Ind. Ecol. 0, 1-11 (2017).

5. EC. Closing the loop - An EU action plan for the Circular Economy. (2015).

6. EMF. Towards the circular economy - Economic and business rationale for an accelerated transition. (2013).

7. Allwood, J. M., Ashby, M. F., Gutowski, T. G. \& Worrell, E. Material efficiency: A white paper. Resour. Conserv. Recycl. 55, 362-381 (2011).

8. Ghisellini, P., Cialani, C. \& Ulgiati, S. A review on circular economy: The expected transition to a balanced interplay of environmental and economic systems. (2015). doi:10.1016/j.jclepro.2015.09.007.This

9. Korhonen, J., Honkasalo, A. \& Seppälä, J. Circular Economy: The Concept and its Limitations. Ecol. Econ. 143, 37-46 (2018).

10. Bocken, N. M. P., Olivetti, E. A., Cullen, J. M., Potting, J. \& Lifset, R. Taking the Circularity to the Next Level: A Special Issue on the Circular Economy. J. Ind. Ecol. 21, 476-482 (2017).

11. Cullen, J. M. Circular Economy: Theoretical Benchmark or Perpetual Motion Machine? J. Ind. Ecol. 21, 483-486 (2017).

12. Van Ewijk, S., Park, J. Y. \& Chertow, M. R. Quantifying the system-wide recovery potential of waste in the global paper life cycle. Resour. Conserv. Recycl. 134, 48-60 (2018).

13. Van Ewijk, S., Stegemann, J. A. \& Ekins, P. Global life cycle paper flows, recycling metrics, and material efficiency. J. Ind. Ecol. 22, 686-693 (2018).

14. IEA. World Energy Balances 2016. (2016).

15. IEA. Energy Technology Perspectives 2016. (2016). doi:10.1787/energy_tech-2014-en

16. Miner, R. \& Perez-Garcia, J. The Greenhouse Gas and Carbon Profile of the Global Forest Products Industry. For. Prod. J. 57, 80-90 (2007).

17. Allwood, J. M., Cullen, J. M. \& Milford, R. L. Options for achieving a 50\% cut in industrial carbon emissions by 2050. Environ. Sci. Technol. 44, 1888-94 (2010).

18. FAO. Impact of the global forest industry on atmospheric greenhouse gases. FAO For. Pap. 159, (2010).

19. Subak, S. \& Craighill, a. The contribution of the paper cycle to global warming. Mitig. Adapt. Strateg. Glob. Chang. 4, 113-135 (1999).

20. OECD. GDP long-term forecast (indicator). (2017). doi:10.1787/d927bc18-en 
References

21. UN. World Population Prospects: The 2015 Revision, Key Findings and Advance Tables. Working Paper ESA/P/WP.241 (2015). doi:10.1017/CBO9781107415324.004

22. FAO. FAO Stat - Forestry Production and Trade. (2019).

23. UNEP. Exploring the potential for adopting alternative materials to reduce marine plastic litter. (2017).

24. Clarke, L. E. et al. Assessing transformation pathways. in Climate Change 2014: Mitigation of Climate Change. Contribution of Working Group III to the Fifth Assessment Report of the Intergovernmental Panel on Climate Change 413-510 (Cambridge University Press, 2014).

25. Merrild, H., Damgaard, A. \& Christensen, T. H. Life cycle assessment of waste paper management: The importance of technology data and system boundaries in assessing recycling and incineration. Resour. Conserv. Recycl. 52, 1391-1398 (2008).

26. US Environmental Protection Agency. Documentation for Greenhouse Gas Emission and Energy Factors Used in the Waste Reduction Model (WARM). (2015).

27. Schmidt, J. H., Holm, P., Merrild, A. \& Christensen, P. Life cycle assessment of the waste hierarchy-a Danish case study on waste paper. Waste Manag. 27, 1519-30 (2007).

28. Pan, Y. et al. A large and persistent carbon sink in the world's forests. Science 333, 988-993 (2011).

29. FAO. FAO assessment of forests and carbon stocks, 1990-2015. (2015).

30. Köhl, M. et al. Changes in forest production, biomass and carbon: Results from the 2015 UN FAO Global Forest Resource Assessment. For. Ecol. Manage. 352, 21-34 (2015).

31. Geist, H. J. \& Lambin, E. F. Proximate Causes and Underlying Driving Forces of Tropical Deforestation. Bioscience 52, 143 (2002).

32. Lewis, S. L., Edwards, D. P. \& Galbraith, D. Increasing human dominance of tropical forests. Science (80-. ). 349, (2015).

33. Heath, L. S. et al. Greenhouse Gas and Carbon Profile of the U. S. Forest Products Industry Value Chain. Environ. Sci. Technol. 44, 3999-4005 (2010).

34. Villanueva, a \& Wenzel, H. Paper waste - recycling, incineration or landfilling? A review of existing life cycle assessments. Waste Manag. 27, S29-46 (2007).

35. Finnveden, G. \& Ekvall, T. Life-cycle assessment as a decision-support too - The case of recycling versus incineration of paper. Resour. Conserv. Recycl. 24, 235-256 (1998).

36. Laurijssen, J., Marsidi, M., Westenbroek, A., Worrell, E. \& Faaij, A. Paper and biomass for energy? The impact of paper recycling on energy and $\mathrm{CO} 2$ emissions. Resour. Conserv. Recycl. 54, 1208-1218 (2010).

37. IEA. Tracking Industrial Energy Efficiency and CO2 Emissions. (2007).

38. Jepsen, D. \& Tebert, C. Best Available Techniques in the Printing Industry. (2003).

39. IPCC. Carbon dioxide intensities of fuels and electricity for regions and countries. (2008).

40. IEA. Electricity Information: World Electricity and Heat Supply and Consumption, 1960-2014 (Data downloaded: 23 February 2017). (2015).

41. IEA. CO2 Emissions From Fuel Combustion: Allocation of Emissions from Electricity and Heat (Data downloaded: 23 February 2017). (2015). 
References

539

540

541

42. Pipatti, R. \& Svardal, P. Solid waste disposal. in 2006 IPCC Guidelines for National Greenhouse Gas Inventories (ed. Task Force on National Greenhouse Gas Inventories) (2006).

43. Macknick, J. Energy and CO2 emission data uncertainties. Carbon Manag. 2, 189-205 (2011).

44. Wiesenthal, T. et al. Technology Learning Curves for Energy Policy Support. JRC Scientific and Technical Reports (2012). doi:10.2790/59345

45. Neij, L. Use of experience curves to analyse the prospects for diffusion and adoption of renewable energy technology. Energy Policy 25, 1099-1107 (1997).

46. Krawiec, F., Thornton, J. \& Edesess, M. Investigation of learning and experience curves. (1980).

47. Weiss, M., Junginger, M., Patel, M. K. \& Blok, K. A review of experience curve analyses for energy demand technologies. Technol. Forecast. Soc. Change 77, 411-428 (2010).

48. Brucker, N., Fleiter, T. \& Plötz, P. What about the long term? Using experience curves to describe the energy-efficiency improvement for selected energy-intensive products in Germany. ECEEE Ind. summer study Proc. 341-352 (2011).

49. Ramírez, C. A. \& Worrell, E. Feeding fossil fuels to the soil: An analysis of energy embedded and technological learning in the fertilizer industry. Resour. Conserv. Recycl. 46, 75-93 (2006).

50. USEPA. Global Mitigation of Non-CO2 Greenhouse Gases. EPA-430-R-13-011 Sept. 2013 (2013). doi:EPA-430-R-13-011

51. IPCC. Climate Change 2014 Synthesis Report. Climate Change 2014: Synthesis Report. Contribution of Working Groups I, II and III to the Fifth Assessment Report of the Intergovernmental Panel on Climate Change (2014). doi:10.1017/СВO9781107415324 